\title{
APROXIMACIONES JURÍDICO-POLÍTICAS SOBRE EL PRINCIPIO DE SEPARACIÓN DE PODERES DEL ESTADO
}

\author{
Enrique Díaz Bravo* \\ Universidad Central de Chile, Abogado
}

Resumen: En presente artículo el autor analiza el surgimiento del Estado en su etapa capitalista y las condiciones que lo provocan, transitando desde el feudalismo y la concepción de la desigualdad natural de los individuos, hasta la construcción de la idea política de igualdad de los individuos, como presupuesto para establecer un nuevo sistema de relaciones de poder. El nuevo orden se articula por un centro que distribuye el poder en varias funciones delegadas, a fin de evitar la concentración del poder.

Palabras clave: poder, estado, sociedad, soberanía, separación de poderes

\section{Legal and political approaches about the principle of separation of powers of the state}

Abstract: In this article the author examines the emergence of the State in its capitalist stage and the conditions that cause it, ranging from feudalism and the conception of the natural inequality of individuals, until the construction of the political idea of equality of individuals, as a presupposition for establish a new system of power relationships. The new order is articulated by a center who distributes the power in various delegated functions, so as to avoid the concentration of power.

Keywords: power, state, society, sovereignty, separation of powers

SUMARIO: 1.PODER, SOCIEDAD Y ESTADO, MARCO TEÓRICO; 2.EL PODER COMO ELEMENTO CONSTITUTIVO DEL ESTADO, LA SOBERANÍA; 3.LA SEPARACIÓN DE PODERES; 4.BIBLIOGRAFÍA.

\footnotetext{
* Licenciado en Ciencias Jurídicas y Sociales, Universidad Central (Chile). Abogado por la Excma. Corte Suprema de Justicia de Chile. Máster Universitario en Derecho Constitucional, Universidad de Sevilla (España). Máster Universitario en Estudios Hispánicos, Universidad de Cádiz (España). Egresado del Máster en Evaluación de Políticas Públicas, Universidad Internacional de Andalucía (España). E-mail: enriquediaz@temasconstitucionales.com.
} 


\section{PODER, SOCIEDAD Y ESTADO, MARCO TEÓRICO}

"El poder encierra en sí mismo la semilla de su propia degeneración Esto quiere decir que cuando no está limitado, el poder se transforma en tiranía y en arbitrario despotismo." [Karl Loewenstein, Teoría De La Constitución]

La posición del individuo, en las denominadas sociedades pre capitalistas, era ilustrada por Aristóteles, quien sentenciaba que el hombre es un animal social y que la interacción con otros individuos lo distingue de las bestias y los dioses, lo que pondría de relieve el carácter natural y axiomático de la sociedad. Del mismo modo, Santo Tomás sostenía que inherente es a la naturaleza del hombre ser social y es creado para ser regido por leyes sociales.

Como se ha sostenido, entonces, la existencia de la comunidad y de la naturaleza social del hombre se da por natural, del mismo modo que la existencia de diferencias entre los individuos y, que dichas diferencias establecen, o provocan, naturales y necesarias relaciones de dominación. Tanto Aristóteles como Santo Tomás, sostenían con diversos matices esta tesis, la que explica las condiciones de supra y sub ordinación de carácter político existentes entre los individuos como connaturales a las demás características del hombre. ${ }^{1}$

Asimismo, sostenía el macedonio, que las relaciones sociales se dan en distintos grados: las de primer grado, o civiles, son entre individuos de distinta categoría social, amos y esclavos; y las de segundo grado, o políticas, son entre hombres libres, o que se pertenecen a sí mismos. A su vez, hay que distinguir entre los mismos hombres libres, ya que no todos los hombres libres son ciudadanos, sólo lo es aquel que participa en la administración de justicia y en el gobierno, y que además, se encuentra exento de la realización de los denominados "trabajos necesarios", que son aquellos de producción de las condiciones materiales de existencia del individuo, por lo que ciudadanos son sólo aquellos que, siendo libres, se dedican a la actividad superflua, la política.

Por tanto, la actividad ciudadana y la actividad política es realizada por los mismos; no sólo existe una identificación en los fines, sino que en los mismo

\footnotetext{
${ }^{1}$ Cabe realizar la distinción respecto a que la subordinación está ligada a las condiciones de producción de la época, es decir los propietarios de los medios de producción tienen una relación con el trabajador, por la que este último se encuentra ligado por dependencia personal a aquel, en virtud de su relación política o, por su distinta ubicación en la natural posición del hombre en la sociedad. Así “... la verdad del Estado, el contenido del Estado, está fuera del Estado, reside en las relaciones que mantienen los individuos en la producción y reproducción de sus condiciones materiales de existencia...". PÉREZ ROYO, J. Alcance y límites de la primera crítica de Marx a la teoría clásica del estado. p. 52.
} 
agentes que la desempeñan, lo que permite identificar a los ciudadanos de los esclavos y animales, como sostenía el Aquinate.

Así, el poder en su estado preconstitucional, debe ser entendido como la dominación de unos sobre otros, originado por un fenómeno natural, y producto del principio rector de dicho momento histórico, la desigualdad natural. De este modo, "...el hombre es por naturaleza un animal social y la sociedad es naturalmente una entidad política con relaciones de dominación de las personas sobre las personas" ${ }^{2}$, esta es la génesis y el desarrollo de las sociedades pre estatales o pre capitalistas.

El punto en que podemos identificar el paso de la antigua sociedad pre estatal, con las citadas condiciones, a aquella en la que surge el Estado, es la concepción del carácter artificial de este, lo que es a la vez fundamento y validez del sistema capitalista, el que surge de manera coetánea o instantánea con aquel. En virtud de la ruina del modelo social, político y económico de la época Feudal surge el Estado como forma de organización del poder político, siendo el presupuesto del sistema capitalista, entendido a grosso modo, como relación social de producción.

Cabe tener presente que el sistema de producción Feudal, pre estatal o pre capitalista, se diferencia del estatal o capitalista, como sistema de producción dominante, en dos supuestos de existencia: 1) La propiedad de los medios de producción; y, 2) El tipo de relaciones entre los individuos en la sociedad. En el primer caso, la propiedad debe ser privada; y en el segundo, las relaciones deben desarrollarse en un plano de hipotética igualdad, o bien, igualdad formal, de status en las relaciones; todos son propietarios, bien sea de los medios de producción o, al menos, de su fuerza de trabajo ${ }^{3}$. Es aquel pie de igualdad de los individuos que permite la construcción de la Teoría del Contrato Social.

A partir de dicha concepción, o al menos anhelo de igualdad, se desarrollan diversas teorías para explicar el Estado, que incluyen posiciones originarias, condiciones o cláusulas contractuales, así como también se explican las relaciones que se originan en la sociedad estatal a partir de las figuras del pactum societatis y el pactum subjectionis. Se marca, entonces, un importante punto de inflexión con la concepción pre estatal de la sociedad, de modo que "lo que era el punto de partida para la teoría política pre estatal, el pactum subjectionis, es el punto de llegada para la teoría política estatal". 4

\footnotetext{
${ }^{2}$ PÉREZ ROYO, J. Introducción a la teoría del estado. p. 127.

${ }^{3}$ Sostiene Pérez Royo que "...los individuos en la sociedad capitalista no están vinculados por relaciones de supra y subordinación política, sino que se relacionan en cuanto individuos con el mismo status jurídico formal, en cuanto individuaos libres e iguales. El poder de las personas sobre las personas, las relaciones de señorío y servidumbre no están presupuesta, sino que están expresamente excluidas de las relaciones de producción capitalista. Ahora bien, una vez definidos todos los individuos sin excepción como ciudadanos, es decir, como individuos libres e iguales, es evidente que las relaciones que tiene que existir entre ellos sólo pueden consistir en el cambio efectuado a través de un acuerdo de voluntades, de un contrato. Pues cualquier otro tipo de relación supondría una vinculación entre dos individuos diferentes de la que procedería de los principios de libertad e igualdad". PÉREZ ROYO, J. Alcance y límites de la primera crítica de MarX a la teoría clásica del estado, p. 51-76.

${ }^{4}$ PÉREZ ROYO, J. Introducción a la teoría del estado. p. 38.
} 
Así, para Hobbes, Locke y Kant el pacto es un solo acto, el que comprende a su vez el pactum societatis como el subjectionis, por el que los individuos se someten a un poder político consentido y diferente de todos ellos.

Jean Jacques Rousseau, en cambio, sostiene que los actos son distintos, toda vez que la asociación que protege y defiende la persona y los bienes de los individuos, se forma exclusivamente a través del pactum societatis, manteniéndose cada uno tan libre como en el estado de naturaleza. La interesante construcción sobre el origen del Estado que hace Rousseau se sostiene por medio de una lógica dialéctica, entendida en base al principio de que "cada uno de nosotros pone en común su persona y todo su poder bajo la suprema dirección de la voluntad general y recibe corporativamente a cada miembro como parte indivisible del

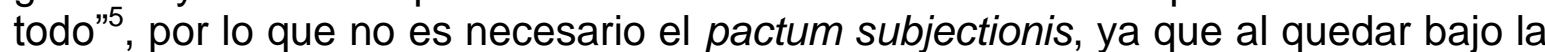
dirección suprema de la voluntad general, entendida como la reunión de todos y cada uno de los miembros de la comunidad, que forman parte indivisible del todo, y debido a que no obedezco a un tercero extraño, me obedezco a mi mismo representado en la voluntad general. Como ciudadano se es siempre parte de la voluntad general, como particular se tiene voluntad individual, la que puede o no ser acorde a aquella. La explicación a esta aparente inconsistencia, la encontramos en el contenido del pacto, de manera que los hombres deben unirse a fin de proteger a los débiles contra los opresores, proteger la propiedad de lo que a cada uno pertenece, y principalmente la elaboración de normas de convivencia pacífica, armónica y justa, que sometan igualmente al rico como al pobre a obligaciones recíprocas. Lo anterior queda consagrado en dichos de Rousseau, en una palabra en lugar de volver nuestras fuerzas contra nosotros mismos, concentrémoslas en un poder supremo que nos gobierne con sabias leyes, que proteja y defienda a todos los miembros de la asociación, rechace a los enemigos comunes y nos mantenga en eterna concordancia.

Por otra parte, nos encontramos con G.W.F. Hegel, quien planteaba que el Estado es una institución que tiene que tener una justificación absoluta, por lo que no comparte los planteamientos que otorgan al Contrato Social el carácter de instrumento iniciador del Estado, considerándolo, en palabras del autor, como un hecho histórico sin más. Asimismo, Hegel sostenía que el Estado es la realidad de la libertad concreta, consistente en la realización de la individualidad, caracterizada por sujetos libres y propietarios, tanto de intereses como de derechos, en la medida en que ellos se integran libre y voluntariamente en el Estado. Es un proceso de retroalimentación de sistemas, por una parte de subjetividad individual y por otra la objetividad de la unidad colectiva, expresado en la reunión del interés de la familia y de la sociedad.

Todas estas posiciones han sido criticadas en razón de ser abstracciones del hombre burgués en una situación sin Estado, es decir todo el modelo está construido en base al desarrollo e interacciones del hombre en un estado sin Estado.

5 Ídem, p. 54. 
Seyla Benhabib sostiene que al destruirse las concepciones teleológicas de la naturaleza feudal se altera el orden de la vida, de las relaciones sociales, de la economía y de toda la teoría moral, la que ahora tiene como centro al hombre. Es la justicia la que se convierte en el centro de la teoría moral, de modo que se define "lo que debe ser como aquello en lo que todos tendrían que estar racionalmente de acuerdo con el fin de asegurar la paz civil y la prosperidad (Hobbes, Locke), o bien es derivado el "debe" de la forma racional de la sola ley moral (Rousseau, Kant)". 6

Así, el pacto social es el principal instrumento cuando la igualdad es el presupuesto de la libertad, de modo que al ser iguales, los sujetos llegan a ser libres. Por tanto, ¿cómo se deben relacionar individuos libres e iguales? La fórmula jurídica clásica es el Contrato Social, cual es un acuerdo entre individuos que deciden institucionalizar el poder. Dicha fórmula ha sido el elemento de mayor inclusión de actores sociales desde el siglo XVIII hasta nuestros días, pero se debe consignar que en sus propios orígenes contiene presupuestos de exclusión de sectores de la sociedad. El contrato social originario es, básicamente y para caracterizarlos, entre hombres, blancos y propietarios, lo que deja entrever una de las características principales de su interrelación, la no dependencia, su igualdad, las relaciones de poder existentes, la sumisión y dominación respecto de los no miembros de dicho reducido cuerpo social.

Cuando Carlos Marx identificó la antagonía existente entre las distintas posiciones sociales dentro del Estado, lo realizó por la observación de las relaciones de sujeción producto del sistema de producción. En dicho sistema, como mencionáramos, es necesario, básicamente, que las relaciones de igualdad política de los individuos se reproduzcan en base a su propiedad, y ello en condiciones de desigualdad, unos propietarios de los medios de producción y otros sólo de su fuerza de trabajo; estos últimos deben mantener sus condiciones materiales o de subsistencia para la reproducción de dicha fuerza de trabajo, entendida como mercancía transable. Es por ello que las relaciones sociales son antagónicas en el Estado Capitalista, y en virtud de la necesidad para los propietarios de los medios de producción de que se generen en forma ordena y garantizada, resulta entonces que el poder político es una condición del sistema. Así, el Estado es considerado como aquella ordenación del poder político en un territorio determinado de carácter representativo entre individuos iguales sólo en derechos políticos.

A la luz de la teoría marxista, Pérez Royo sostiene que "El poder político es, por tanto, el instrumento utilizado por la clase dominante en los diferentes modos de producción precapitalista para apropiarse el excedente producido por los trabajadores directos. Esto presupone necesariamente no sólo la desigualdad fáctica de los individuos, sino la desigualdad jurídica de los mismos, así como también la desconcentración de las relaciones políticas, que se dispersan en tantos puntos como se desarrolla el proceso productivo". Prosigue luego ilustrando

\footnotetext{
${ }^{6}$ BENHABIB, Seyla, "El otro generalizado y el otro concreto: la controversia Kohlberg-Gilligan y la teoría feminista" en BENHABIB, Seyla y CORNELL, Drucilla. Teoría feminista y teoría crítica: Ensayos sobre la política de género en las sociedades de capitalismo tardío. p. 130.
} 
lo que ocurre en el modo de producción capitalista “... desaparecen los caracteres de supra y sub ordinación política que marcaban las relaciones personales de todos los modos de producción precapitalistas. Los individuos se relacionan como individuos con el mismo status jurídico formal, como individuos a secas". 7

Por su parte B. González Alonso sostenía que "La transición del feudalismo al capitalismo se concreta inmediatamente en la transición del Estado absoluto al Estado constitucional, porque la sustitución del organización política absolutista por la constitucional resume y constituye la culminación de la compleja serie de cambios que, tanto en el plano ideológico como en el organizativo, tuvieron lugar desde los primeros años del siglo XIX".

Por otra parte, Karl Loewenstein (1976) explicaba que la sociedad es un sistema de relaciones de poder que puede ser de diversos caracteres (político, social, económico, religioso, moral, cultural o de otro tipo). Consideraba al poder como una relación socio psicológica basada en un recíproco efecto entre los que detentan o ejercen el poder y aquellos a los que va dirigido. El poder político surge en la sociedad estatal como el ejercicio de un efectivo control social de los detentadores del poder sobre los destinatarios del poder. Así, dicho poder ha tendido a establecerse a través de su implantación por medio de normas, transformando la fuerza en derecho y la obediencia en deber. Es así como la ordenación del poder se ha traducido en la Constitución, declaración política primero y norma jurídica después, como proceso de ordenación y racionalización del poder político.

El jurista alemán se planteaba dos observaciones respecto del elemento poder. La primera trata sobre la preeminencia que dicho elemento tiene, no sólo sobre la relación entre quienes detentan el poder y sus destinatarios, sino que, y más importante aún, también sostiene que condiciona las relaciones entre los propios detentadores del poder. En segundo lugar planteaba que en el sistema político de una sociedad estatal se deben distinguir tres grados en el proceso político. El primero es la forma en que se obtiene el poder político por quienes lo detentan y su instalación. Segundo, la forma en que será ejercido el poder, la distribución de las funciones. Y tercero, los mecanismos de control del ejercicio del poder político, como límite al ejercicio del poder.

\section{EL PODER COMO ELEMENTO CONSTITUTIVO DEL ESTADO, LA SOBERANÍA}

Ya hemos desarrollado brevemente el entramado en virtud del cual las relaciones de poder han determinado el paso del régimen feudal al surgimiento del Estado denominado liberal. De modo que nos corresponde fijar cual es el rol que el poder, una vez constituido el Estado, juega en dicha institución.

\footnotetext{
${ }^{7}$ PÉREZ ROYO, J. Aproximación al método de la teoría del estado. p. 124.

${ }^{8}$ ALONSO, Benjamín. Del estado absoluto al estado constitucional. p. 81.
} 
El poder, desde el punto de vista del derecho político, es además un elemento constitutivo del Estado, tanto como el pueblo y el territorio. Lucas Verdú señala que "el poder sintetiza, merced a su virtualidad jurídico-política, a los otros dos elementos estatales: el pueblo, elemento personal, y el territorio, factor geofísico" 9 . Hans Kelsen (1945), por su parte, sostiene que el poder es usualmente incorporado como el tercer elemento del Estado, de modo que es la sujeción de los elementos (Un Estado, un territorio, un pueblo y un poder) a un poder que reconociendo la existencia de otros poderes similares, no admite otro coincidente, lo que ha sido conceptualizado como Soberanía, cual es la que permite que el Estado se manifieste como una entidad única, como una unidad.

El poder en sí mismo no basta, todo poder debe tender a institucionalizarse para lograr permanecer en el tiempo, y no basta cualquier tipo de institucionalización, debe realizarse mediante formas legítimas. H. Heller lo explica con toda claridad señalando que "Sólo goza de autoridad aquel poder del Estado a quien se le reconoce que su poder está autorizado. Su autoridad se basa únicamente en su legalidad en tanto, esta se fundamenta en la legitimidad."

Respecto a la manifestación del poder, como elemento constituyente del Estado, la soberanía significa poder de organización territorial suprema y exclusiva, donde, como sostiene Lucas Verdú, el Estado es creador supremo de las normas y tiene el monopolio del poder de coacción física, lo que se considera la última ratio de todo poder.

Jellinek, por su parte, sostenía que "la soberanía es, en su origen histórico, una concepción de índole política, que sólo más tarde se ha condensado en una índole jurídica"11, en cuyo proceso se enfrentan distintos poderes y fuerzas sociales; es una triple lucha "contra la Iglesia, el imperio y los señores feudales". ${ }^{2}$ Así, la soberanía requiere de su formalización mediante los instrumentos jurídicos, que indiquen la residencia de la misma y de los órganos que la ejercen, continua Lucas Verdú, ya que es través de las normas jurídicas mediante las cuales se indica quien es el soberano. ${ }^{13}$

Por su parte, Loewenstein (1976) sostiene que la soberanía sería "la racionalización jurídica del factor poder, constituyendo éste el elemento irracional de la política. Según esto, soberano es aquél que está legalmente autorizado, en la sociedad estatal, para ejercer el poder político, o aquel que en último término lo ejerce". En tanto, el consentimiento que los gobernados prestan, no es al titular del

\footnotetext{
${ }^{9}$ LUCAS VERDÚ, Pablo. Curso de derecho político, v. II. p. 108.

${ }^{10}$ Citado en ibíd. p. 113.

11 ibíd. p. 120.

12 Ídem.

${ }^{13}$ Conviene citar algunos ejemplos del lugar de residenciación de la soberanía manifestado en cartas fundamentales de países con distintos sistemas. "La Soberanía nacional pertenece al pueblo que la ejerce por medio de sus representantes y mediante referéndum", Art. 3 de la Constitución francesa de 1958; "La soberanía nacional reside en el pueblo español, del que emanan los poderes del Estado", Art. 1, № 2 de la Constitución española de 1978; "La soberanía reside esencialmente en la Nación, su ejercicio se realiza por el pueblo a través del plebiscito y de elecciones periódicas y, también, por las autoridades que esta Constitución establece”, Art. 5, Constitución Política de la República de Chile de 1980.
} 
poder del momento, sino que el consentimiento prestado dice relación con la Institución que es ejercida por los gobernantes, de lo contrario, se pondría en tela de juicio el fundamento de la autoridad en cada transmisión de poder (Lucas Verdú, 1986).

\section{LA SEPARACIÓN DE PODERES}

La transformación de las ideas sobre el papel del Estado fue paralela a un cambio sobre la naturaleza de la soberanía. Así, los teóricos del absolutismo resaltaban la necesidad de que el poder dependiera de una instancia única y omnipotente, lo que era rechazado por los constitucionalistas liberales, como veremos en los párrafos siguientes. Los defensores de la libertad frente a los sistemas de gobierno arbitrario abogaban por la división de poderes y proponían establecer limitaciones al poder por medio de una Constitución o ley superior. Cuando J.J. Rousseau asoció la idea de soberanía ilimitada al pueblo y no a la monarquía, se produjo un cambio de rumbo. Si el poder absoluto residía en el pueblo o en sus representantes, podía eliminarse su tradicional asociación con los sistemas de gobierno arbitrario para reciclarlo como instrumento de poder democrático. Volveremos a esto más adelante.

M. J. Vile (2007) al analizar la evolución de las ideas relativas a la separación de poderes, formuló la denominada doctrina pura, la que permite una clara ilustración. Ella se explica como una forma "...esencial para el establecimiento y conservación de la libertad política (en la) que el Estado se divida en tres ramas o departamentos, llamados cuerpo legislativo, cuerpo ejecutivo y cuerpo judicial. A cada una de estas tres ramas corresponde una función, que lleva su mismo nombre. Cada rama del Estado debe limitarse a ejercer la función que le es propia, sin que se le permita interferir en las funciones de las otras dos ramas. Además, las personas que componen cada una de estas tres agencias deben ser diferentes, sin que se permita que un solo individuo forme parte de más de una rama simultáneamente. De este modo, cada una de las tres ramas controlará a las dos restantes, y el manejo de la maquinaria del Estado nunca podrá estar en manos de una solo grupo de individuos"14. Esta versión representa una especie de modelo ideal, o patrón maestro, como punto de referencia, ya que tal versión de la doctrina no es defendida en la teoría ni puesta en práctica.

Uno de los inconvenientes, si puede considerarse así, que representa esta doctrina pura de separación de poderes es su compromiso con la libertad política o su rechazo al poder arbitrario. Esto debido a que los conceptos de libertad se asocian a una visión esencialmente negativa de la libertad política, concebida como la ausencia de restricciones más que como una idea formulada en términos positivos. La preocupación por adoptar medidas que protejan las libertades individuales lleva a adoptar medidas que debilitan al Estado, hasta el punto de ser

\footnotetext{
${ }^{14}$ VILE. Constitucionalismo y separación de poderes. p. 14.
} 
incapaz de proporcionar los requisitos sociales y económicos básicos para que todo individuo pueda ejercer libremente su poder de decisión. ${ }^{15}$

La doctrina de la separación de poderes lleva consigo una concepción de libertad política que tiene como elemento esencial la restricción del poder estatal, estableciendo divisiones en su interior para evitar concentraciones de poder, aún cuando debe tener el Estado cierta fortaleza para garantizar dicha libertad política, y sobre las posibles vías para compatibilizar los principios básicos de la doctrina

${ }^{15}$ Sobre esta materia fue Isaiah Berlin quien realiza planteamientos claros sobre los dos conceptos
de libertad. En principio se plantea que la teoría política "es una rama de la filosofía moral que
tiene su origen en el descubrimiento, o aplicación, de ideas morales en la esfera de las relaciones
políticas". A partir de esta premisa es que comienza a preguntarse sobre el problema central de la
política, el desenvolvimiento del hombre, tanto en el plano de su privacidad o bien en el plano de lo público, y de la posibilidad y modos de ser coaccionado.

Así, desemboca en el análisis del concepto de libertad, considerada en su sustrato político, abordándola desde su doble perspectiva, positiva y negativa. La Libertad Negativa entendida como aquel espacio en que se desenvuelve el individuo sin la "interferencia" u obstáculo de otros, por medio de actos u omisiones deliberadas no de la naturaleza. La libertad en este sentido se encontraría determinada por cuantas posibilidades de elección existen, de la viabilidad de ellas, de su trascendencia y del valor que se les atribuya. Por tanto no tiene que ver, exclusivamente, con las condiciones materiales de realización de las distintas posibilidades, pues la falta de condiciones no elimina la libertad, sólo imposibilitaría su ejercicio.

Berlin plantea, así mismo, el concepto de Autonomía del Individuo, ya no desde el presupuesto determinante de las interferencias, sino que partiendo de cuanto espacio existe en cada individuo para ser señor de sí mismo, la identificación del yo individual que, sin concebirlo como algo que va más allá del individuo, es decir sin hacerlo parte de la totalidad, le permitirá elegir o decidir sus destinos en consideración a las posibilidades que el ejercicio de la libertad negativa le permite representarse. Este es el concepto de Libertad Positiva, cual sería coaccionado por la separación del individuo en dos yoes, uno superior y otro que estaría dominado por la irracionalidad. El superior se difuminaría entre los distintos yoes colectivos. En este caso se perdería la libertad positiva, ya que se produciría el efecto contrario a la Autonomía, ya que mientras mayor sea aquella más libre será el individuo. El individuo racional en la sociedad ideal debe conservar los amplios márgenes de acción para alcanzar su único fin, cual es el autogobierno racional que sostiene que la única libertad que merece este nombre es la de buscar nuestro propio bien, por nuestro camino propio.

En sus recurrentes referencias a Mill comenta que si no se permite a cada hombre vivir como quiera, en la parte que le concierne a él, la sociedad no avanzará, se quedará estancada, es decir la libertad negativa se consigna en la defensa de toda interferencia en el plano individual con serias implicancias sociales si hay interferencias, ya que no hay ninguna actividad humana que sea realmente privada debido a la relación sistémica de la interacción entre los individuos.

La libertad negativa es la ausencia de obstáculos de carácter político, es decir de creación humana. Se supone que los hombres son libres por las condiciones en la que ingresan al Estado, que aseguran individuos iguales y libres. La libertad negativa no desaparece nunca, ya que es la razón porque los individuos ingresan a la Sociedad. La única derivación del principio de igualdad es la anarquía, pero empíricamente está demostrado que es imposible, toda vez que siempre se necesita organización del poder. La mayoría de los obstáculos no provienen del Estado para ejercer la libertad, sino que de otros individuos. Con la libertad negativa no se puede organizar la vida en sociedad, ya que hay que tomar decisiones y ahí se encuentra la libertad positiva. ¿Quién determina las Normas Jurídicas y las demás condiciones de la sociedad? Esta es la esencia del debate político y no deja de producirse en todas las sociedades. La democratización del Estado se provoca cuando el conjunto de ciudadanos ingresan al Pacto Social. La menor libertad de algunos en pos de la libertad mayoritaria es uno de los objetos del Pacto Social, considerando como condición de ello que sin garantías para el ejercicio de la libertad negativa no hay sociedad civil. BERLIN, Isaiah. Dos conceptos de libertad. 
con los requerimientos mínimos que deben cumplir los Estados. El profesor Elías Díaz sostiene que "La separación de poderes constituye, en efecto, el resultado histórico de la lucha contra el absolutismo de los reyes en nombre de los derechos del pueblo: legislativo popular, pues, intentando limitar el poder omnímodo del ejecutivo, en amplia medida dominado por el rey. $\mathrm{Y}$ junto a ello, lucha por la independencia de la función judicial. El sentido histórico e ideológico del principio de la separación de poderes es, así, evitar la concentración de poder en manos, sobre todo, del titular del poder ejecutivo, a fin de lograr el respeto a los derechos y libertades de los ciudadanos que, representados democráticamente, constituyen ahora el poder legislativo". ${ }^{16}$

Así, encontramos como primer elemento de la doctrina, el establecimiento de una división que distribuye a los elementos constitutivos del Estado en tres categorías: legislativa, ejecutiva y judicial. ${ }^{17}$ M. J. C. Vile (2007) lo justifica con toda claridad sosteniendo que "La dispersión de la autoridad entre diferentes centros con capacidad para la toma de decisiones es la antítesis del totalitarismo o el absolutismo."18

El segundo elemento de esta doctrina es que existen tres "funciones" específicas del Estado. Se establece que en todos los sistemas de gobierno se deben llevar a cabo tres funciones, tanto si recaen en la misma persona o grupo como si no lo hacen, y tanto haya o no una división de estas funciones entre dos o más agencias. Así, todas las acciones del Estado pueden encuadrarse dentro del ejercicio de la función legislativa, la ejecutiva o la judicial. Esto es una perspectiva de las funciones del Estado extremadamente abstracta, lo que no debe confundirse con las denominadas tareas del Estado, como mantenimiento de la paz, carreteras, o la defensa del país. ${ }^{19}$

Al tercer elemento de la doctrina, a pesar de ser discutido, se le denomina separación de personas. Esto se refiere a que las tres ramas del Estado estén integradas por grupos de personas separados y distintos, sin que un solo individuo pueda pertenecer simultáneamente a varias ramas. Para garantizar la libertad, cada una de las funciones debe encontrarse en manos de diferentes personas. "EI elemento final de la doctrina es que si se siguen las indicaciones sobre las instituciones, las funciones y las personas, cada rama del Estado constituirá un elemento de control que prevenga el ejercicio arbitrario del poder por parte de las otras dos, y que dado que cada rama estará limitada al ejercicio de la función que

\footnotetext{
${ }^{16}$ DÍAZ, Elías. Estado de derecho y sociedad democrática. p. 47.

17 Vile (2007) nos recuerda que John Sadler proponía, religiosamente, en 1649 como base de la estructura tripartita del Estado la estructura divina, de este modo se preguntaba: " $Y Y$ por qué no habría de estar representada la Santísima Trinidad en nuestros órganos políticos, así como los está en los naturales?'.

${ }^{18}$ VILE. Constitucionalismo y separación de poderes, p. 16.

19 En la época anterior de que Locke y Montesquieu plantearan esta visión abstracta de las funciones del Estado existían dos corrientes de pensamiento. La primera de ellas usaba el término poderes para definir la función de legislar y la de poner las leyes en ejecución; la segunda mantenía una perspectiva más práctica de las acciones del Estado, dividiendo los atributos de la soberanía en varias categorías, así se incluían funciones como la de acuñar moneda, entre otros.
} 
le es propia, ninguna de ellas podrá ejercer una influencia o presión indebida sobre las dos restantes.", sostiene Vile ${ }^{20}$.

La denominada doctrina pura concibe el control del poder de una manera negativa, ya que la mera existencia de varias entidades autónomas con capacidad de decisión y funciones específicas es una cortapisa suficiente a la concentración del poder.

Así, la doctrina de separación de poderes no incluía mecanismos de control de las agencias que pretendiesen hacer usos indebidos de su poder interfiriendo en las funciones de otra agencia. Uno de los mecanismos por los que se modifica la doctrina posteriormente es con la teoría del estado mixto o con, su versión posterior, la teoría de pesos y contrapesos. Esto se realizó con el objeto de introducir, a la doctrina de separación de poderes, un conjunto de controles positivos sobre el ejercicio del poder.

Por su parte, Lucas Verdú sostiene que la separación de poderes es "un principio dogmático del Estado constitucional liberal, puesto que considera indispensable para asegurar la libertad de los ciudadanos, en la medida que limita el poder político, atribuyendo a órganos distintos, correspondientes a instituciones diferentes, el ejercicio de cada función estatal de modo que un individuo, un grupo de individuos, o una asamblea, no puedan, al mismo tiempo dictar leyes y aplicarlas por vía administrativa o judicial" ${ }^{21}$, explica el autor que es un principio dogmático porque se afirma la identidad absoluta entre la separación de poderes y el reconocimiento de la libertad. Sin embargo, se ve relativizado su aspecto institucional en la medida en que se redistribuyen los poderes (funciones) entre diversos órganos para contribuir a un estado de equilibrio, igualmente se introducen técnicas de control de la constitucionalidad de las leyes, y algunos mecanismos de democracia semidirecta como el referéndum. ${ }^{22}$

Fue el mismo Montesquieu, señala Lucas Verdú, quien estimaba que el postulado de la separación de poderes no era suficiente para asegurar la libertad; aquella debe ser acompañada por una serie de instituciones que confluyan en la constitución de una sociedad democrática.

Loewenstein (1976), por su parte, afirma que desde Montesquieu se ha sostenido invariablemente, al menos en la teoría, el dogma de la separación de poderes. Así, luego del periodo de entre guerras (siglo $\mathrm{XX}$ ), a juicio del autor no se ha considerado suficientemente a la doctrina de separación de poderes, toda vez que en el mismo parlamentarismo los poderes legislativo y ejecutivo no están

\footnotetext{
20 ibíd. p. 18 - 19.

${ }^{21}$ LUCAS VERDÚ. Curso de derecho político, v. II, p. 133.

22 Respecto a la manifestación del principio de Separación de Poderes en el ordenamiento Español, Lucas Verdú (1986) sostiene que este se encuentra implícito en la Constitución, en primer lugar porque España es un Estado de Derecho el que tiene como característica la separación de poderes; en segundo lugar porque se afirma que la forma política es la monarquía parlamentaria, sistema que se caracteriza por una separación de los poderes, aún cuando no sea de carácter estricto como en los sistemas presidenciales. De este modo la separación de poderes en España impediría la acumulación de funciones por el mismo órgano, e igualmente el factor del modelo de organización territorial favorece la separación vertical de poderes.
} 
separados ni personal ni funcionalmente. Sostiene que lo que en realidad significa la "llamada separación de poderes no es más ni menos, que el reconocimiento de que por una parte el Estado tiene que cumplir determinadas funciones - el problema técnico de la separación del trabajo - y que, por otras, los destinatarios del poder salen beneficiados si estas funciones son realizadas por diferentes órganos: la libertad es el telos ideológico de la teoría de la separación de poderes. La separación de poderes no es sino la forma clásica de expresar la necesidad de distribuir y controlar respectivamente el ejercicio del poder político". El autor prefiere el término separación de funciones en vez de separación de poderes, ya que a su juicio se ha producido en muchos casos integración de poderes, sostiene que "el concepto de poderes debe ser entendido... de una manera meramente figurativa". ${ }^{23}$

Kelsen (1945), a su vez, indicaba que el concepto de separación de poderes se refiere a un principio de organización política el que está diseñado de modo que existan tres poderes teniendo cada uno una función asignada, las que funciones coordinadamente en el Estado, y donde es posible establecer y definir claramente cuáles son los limites y competencias de cada uno frente al otro, lo que, en palabras de H. Kelsen no está apoyado por los hechos.

En los Estados Unidos de Norteamérica se emplea comúnmente la designación de un gobierno de separación de poderes (Loewenstein 1976), de separación y coordinación de poderes, calificado y clasificado, igualmente, como un gobierno de tipo presidencial.

El modelo de estricta y rígida separación de poderes (funciones según prefiere Loewenstein como hemos señalado) que tanto en los Estados Unidos como en Francia se manifestaron con fuerza, es calificado por el autor como "un producto artificial del racionalismo especulativo de la llustración, debiendo su nacimiento al traspaso de los principios mecanicistas de la física de Newton a la realidad sociopolítica"24, destinada a producir una suerte de armonía que permitiera convivir e interactuar a los distintos detentadores del poder. El autor sostiene que el presidencialismo norteamericano ha innovado lo suficiente como para sostener que ha superado la división clásica de funciones o poder, gobierno, legislación, judicial, de modo una nueva división tripartita en: determinación de la decisión, ejecución de la decisión y control político. Esto fundamentado en que la mayoría de las decisiones políticas fundamentales son de iniciativa del presidente, no obstante independiente de la procedencia de la iniciativa deben resolver en común dichas iniciativas, $o$ en su defecto coordinadamente, ya sea por materias presupuestarias, de política exterior u otras.

El proceso de cambio y desarrollo del modelo de interrelacionarse los individuos y de cómo establecer su sistema de gobierno, no fue fácil, del mismo modo que la propia articulación orgánica de los principios liberales. La evolución de dichos principios y su aplicación en distintas sociedad, todas realizadas con el objeto del control del poder. De modo tal que, como sostiene Pérez Royo "En el proceso de

\footnotetext{
${ }^{23}$ LOEWENSTEIN, Karl. Teoría de la constitución. p. 56.

${ }^{24}$ ibíd. p. 71.
} 
imposición y de desarrollo inicial del Estado en el continente europeo, a lo más que se llegaría es a la afirmación abstracta de los derechos fundamentales, y de la división de poderes como condición necesaria, pero también suficiente, para controlar el ejercicio del poder estatal, identificándose con ellos el propio concepto de Constitución (art. 16 DDHC). El tránsito de la política al derecho todavía estaba muy lejos."25

\section{BIBLIOGRAFÍA}

(1987) ALONSO, Benjamín, "Del estado absoluto al estado constitucional", Manuscrits: Revista d'Història Moderna, no. 4, ISSN 0213-2397, pp. 81-90.

(1990) BENHABIB, Seyla, "El otro generalizado y el otro concreto: la controversia Kohlberg-Gilligan y la teoría feminista" en BENHABIB, Seyla, y CORNELL, Drucilla, Teoría Feminista y Teoría Crítica: Ensayos sobre la política de género en las sociedades de capitalismo tardío, Edicions Alfons el Magnànim, Institució Valenciana d'Estudis i Investigació, Valencia.

(2008) BERLIN, Isaiah, Dos Conceptos De Libertad, Ed. Alianza Editorial, Madrid.

(1998) DÍAZ, Elías, Estado De Derecho y Sociedad Democrática, Ed. Taurus, Madrid.

(1945) KELSEN, Hans, General theory of law and state. Reprinted, Ed. Cambridge., Cambridge.

(1976) LOEWENSTEIN, Karl, Teoría de la constitución, Ed. Ariel, Barcelona.

(1986) LUCAS VERDÚ, Pablo, Curso de derecho político, v. II, 3 reimp, Ed. Tecnos, Madrid.

(1992) PÉREZ ROYO, Javier, "Del derecho político al derecho constitucional: las garantías constitucionales", Revista Del Centro De Estudios Constitucionales, no. 12, ISSN 0214-6185, Madrid, pp. 233-249.

(1979) PÉREZ ROYO, Javier, "Aproximación al método de la teoría del Estado", Revista De Estudios Políticos, no. 11, ISSN 0048-7694, Madrid, pp. 52-130.

(1978) PÉREZ ROYO, Javier, "Alcance y límites de la primera crítica de Marx a la teoría clásica del Estado", Revista De Estudios Políticos, no. 5, ISSN 0048-7694, Madrid, pp. 51-76.

(1980) PÉREZ ROYO, Javier, Introducción a la teoría del estado, Ed. Blume, Barcelona.

(2007) VILE, M. J. C, Constitucionalismo y Separación De Poderes. Ed. Centro de Estudios Políticos y Constitucionales, Madrid.

\footnotetext{
${ }^{25}$ PÉREZ ROYO, J. Del derecho político al derecho constitucional: Las garantías constitucionales. p. 236.
} 